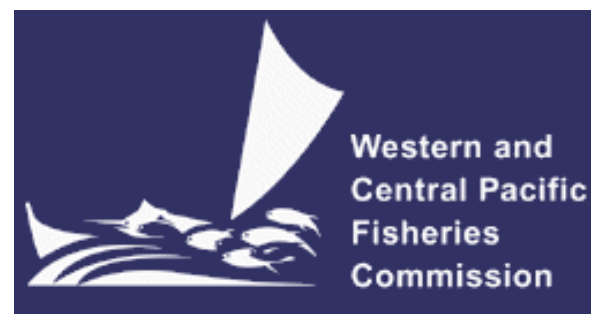

SCIENTIFIC COMMITTEE FOURTH REGULAR SESSION

11-22 August 2008

Port Moresby, Papua New Guinea

CCAMLR PROCESS OF RISK ASSESSMENT TO MINIMISE THE EFFECTS OF

LONGLINE FISHING MORTALITY ON SEABIRDS

WCPFC-SC4-2008/EB-IP-1

S.M. Waugh ${ }^{1}$, G.B. Baker ${ }^{2}$, R. Gales ${ }^{3}$, J.P. Croxall ${ }^{4}$

\footnotetext{
${ }^{1}$ Ministry of Fisheries, PO Box 1020 Wellington, New Zealand

${ }^{2}$ Institute of Antarctic and Southern Ocean Studies, University of Tasmania, Private Bag 77, Hobart, Tasmania 7001, Australia

${ }^{3}$ Biodiversity Conservation Branch, Department of Primary Industries and Water, PO Box 44, Hobart, Tasmania 7000, Australia

${ }^{4}$ BirdLife International, Wellbrook Court, Girton Road, Cambridge CB3 0NA, UK
} 


\title{
CCAMLR process of risk assessment to minimise the effects of longline fishing mortality on seabirds
}

\author{
S.M. Waugh ${ }^{\mathrm{a}, *}$, G.B. Baker ${ }^{\mathrm{b}}$, R. Gales ${ }^{\mathrm{c}}$, J.P. Croxall ${ }^{\mathrm{d}}$ \\ ${ }^{a}$ Ministry of Fisheries, PO Box 1020 Wellington, New Zealand \\ ${ }^{\mathrm{b}}$ Institute of Antarctic and Southern Ocean Studies, University of Tasmania, Private Bag 77, Hobart, Tasmania 7001, Australia \\ ${ }^{\mathrm{c}}$ Biodiversity Conservation Branch, Department of Primary Industries and Water, PO Box 44, Hobart, Tasmania 7000, Australia \\ ${ }^{\mathrm{d} B i r d L i f e}$ International, Wellbrook Court, Girton Road, Cambridge CB3 ONA, UK
}

Received 23 August 2007; accepted 24 August 2007

\begin{abstract}
We describe the process used in the fisheries management system of the Convention for the Conservation of Antarctic Marine Living Resources (CCAMLR) to minimise seabird bycatch, and the risk-assessment methodology developed to assist this. We examine the progress of several Regional Fishery Management Organisations in taking steps to address seabird bycatch. CCAMLR has the most advanced system of management among the RFMOS covered in this review, and has made the most demonstrable progress in reducing seabird bycatch levels in its longline fisheries. A combination of proven mitigation measures, extensive monitoring by independent observers, annual expert review of seabird bycatch rates and evolving fishery and mitigation practices have been instrumental in reducing seabird bycatch in CCAMLR fisheries.
\end{abstract}

(C) 2007 Elsevier Ltd. All rights reserved.

Keywords: Seabird bycatch; Ecological risk assessment; Regional Fishery Management Organisations; CCAMLR

\section{Introduction}

Incidental mortality of seabirds in longline fisheries is recognised as a key threatening process for seabird species [1-4].

Albatrosses and petrels are wide ranging, with foraging activity taking some individuals thousands of kilometres from their breeding colonies, and migrations at various life-stages taking them across entire ocean basins [5]. This wide distribution and the habit of feeding on fisheries waste and bait leads to seabird mortality in a variety of fisheries, although longline fisheries, and more recently trawl fisheries, are identified as particular threats for long-lived and wide-ranging seabirds [6,7]. The key management regimes for addressing seabird bycatch on these oceanic scales are Regional Fishery Management Organisations (RFMOs) [8]. Until now, the response by RFMOs in implementing measures to address seabird mortality has

\footnotetext{
*Corresponding author. Tel.: + 6449764227.

E-mail address: waugh.filippi@paradise.net.nz (S.M. Waugh).
}

largely been to require mitigation measures such as birdscaring (streamer) lines to be used on longline vessels, although information about implementation of these requirements and their efficacy is generally lacking. In the case of the longline fisheries managed under the Convention for the Conservation of Antarctic Marine Living Resources (CCAMLR), monitoring of the effectiveness of measures at reducing seabird captures, implementation of the measures and ecological risk assessment (ERA) for seabirds have also been used. CCAMLR has been highly effective at reducing seabird bycatch in its longline fisheries. An unequivocal measure of this performance is demonstrated in the annual summary and analysis of seabird bycatch data for the CCAMLR area (Fig. 1), monitored by independent scientific observers.

In 1996, the year of the first (but incomplete) monitoring of seabird captures across the CCAMLR area (Fig. 2), an estimated 6500 birds were killed in two main areas, around South Georgia (CCAMLR area 48.3) and around the Prince Edward Islands (CCAMLR areas 58.6 and 58.7) [9]. Continued improvement in bycatch statistics has been 


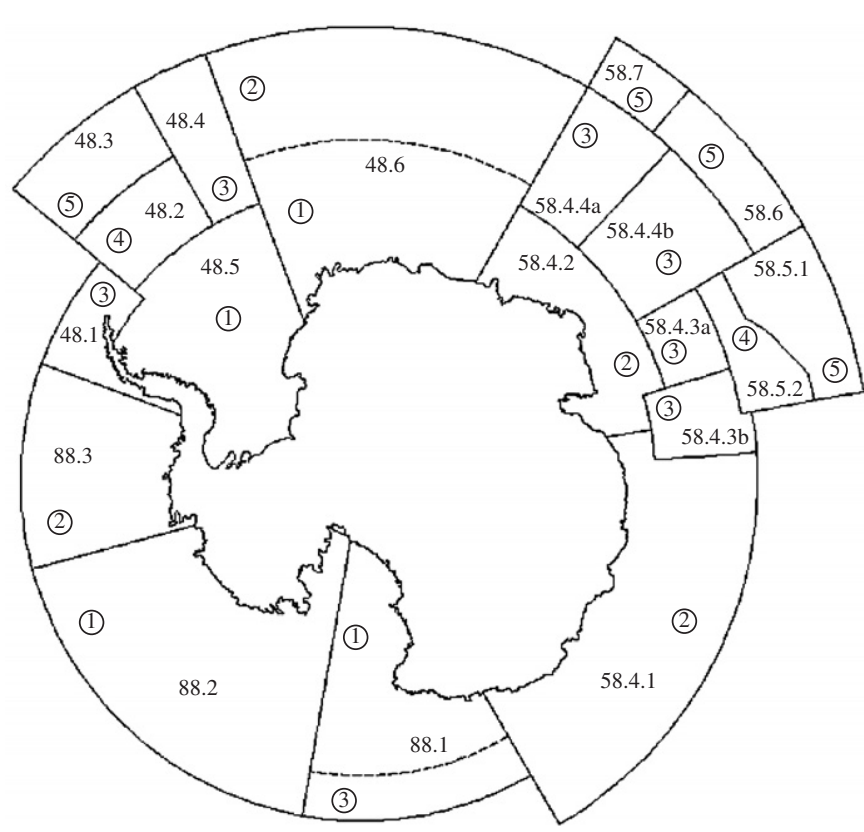

Fig. 1. CCAMLR area showing the Antarctic Continent in the centre, and the location of statistical subareas with numbers in circles representing the risk ratings for each subarea defined in the annual review of 2006 [22].

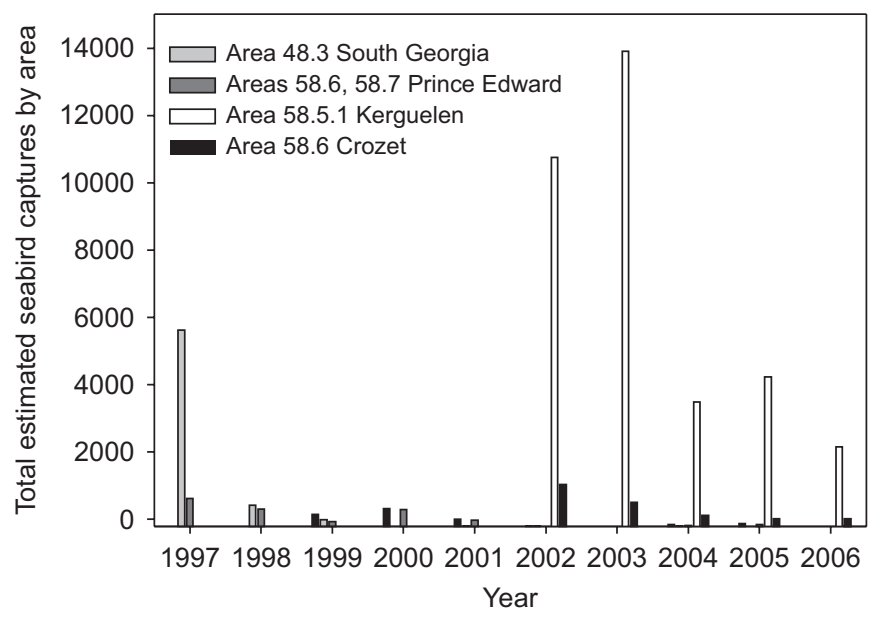

Fig. 2. Seabird captures in the demersal longline fishery for Dissostichus spp. in the CCAMLR area during 1997-2006 for areas managed within CCAMLR regulations where bycatch of more than 10 birds/year has been observed. Prior to 2002, data for areas of the French EEZ (CCAMLR areas 58.6 and 58.5.1) were unavailable, and the first estimates for this year were based on extrapolation over all hooks, rather than the number of hooks observed in the fishery, hence tended to underestimate the total bycatch.

achieved throughout the 10-year period to 2006 when, for these areas, two birds were estimated to have been killed [9]. This change in bycatch was the result of complex processes, in which agreement by the Parties to CCAMLR to reduce fishing seasons in 1997 was a key factor [10], and resulted in a ten-fold reduction in captures between the 1996 and 1997 review periods [4]. More recently, data for the waters in the French Exclusive Economic Zone (EEZ) around the Kerguelen Islands (CCAMLR area 58.5.1) and the Crozet Islands (CCAMLR area 58.6) have been submitted to CCAMLR, and with new line-weighting regimes being employed from 2004, rapid reductions in bycatch have been achieved in those areas too (Fig. 2).

In this paper we describe the process and information used in the CCAMLR-Seabird Risk Assessment (CCAMLR-SRA) for demersal longline fisheries. Recent examples of changes to the information base or management recommendations are given. This description sets out how the CCAMLR-SRA functions currently, rather than attempting to describe the evolution of the methods through time. The CCAMLR-SRA methods are of relevance to other RFMOs, some of which are currently reviewing their seabird mitigation measures, or developing risk-assessment methods for bycatch. We summarise the seabird mitigation provisions of six RFMOs and examine these in the context of the CCAMLR-SRA procedures.

\section{The CCAMLR-Seabird Risk Assessment}

CCAMLR entered into force in 1982, as an international agreement developed by the contracting parties to the Antarctic Treaty System. With 34 parties in 2007, CCAMLR has as a primary function the regulation of fishing activity in the Southern Ocean, where it manages high-value fisheries for Patagonian and Antarctic Toothfish Dissostichus eleginoides and Dissostichus mawsoni, Antarctic Krill Euphausia superba, and other finfish species. Maintenance of the Antarctic ecosystem was a key driver in the formulation of the Convention. Environmental risk from fishing activity was recognised early in the development of CCAMLR, and Article II of the Convention notes that resources in the CCAMLR area should be managed to ensure their conservation, including rational use. These principles are set out so that not only targeted fish stocks, but also other species occurring in the CCAMLR area, are not unduly or adversely affected by fishing activities.

ERA is commonly used in reducing risk to species or habitats as a result of human activities in the environment including fishing [11-14]. The CCAMLR-SRA follows the steps defined in classic ERA $[15,16]$. These are:

(a) establishing the context and problem formulation;

(b) risk assessment through identification, analysis and evaluation of the risks;

(c) management of risk; and

(d) monitoring and review (feedback steps, including data acquisition).

\subsection{Context and problem formulation}

The problem of detrimental environmental effects for CCAMLR fisheries was characterised by a rapidly developing demersal longline fishery in the 1990s - a method known to capture seabirds in high numbers. In particular, the seabirds most vulnerable to longline mortality are low productivity species of albatross and petrel, of which some 
120 species occur in the Southern Ocean [17]. The context for CCAMLR treatment of environmental risk is clearly established through Article II of the Convention which states that ecological relationships must be maintained and changes in harvested or dependent species must not be at a level that require more than two to three decades for stocks to rebuild [18]. These new fisheries were operating in an area with high densities of seabirds, some of which were threatened with extinction. The particular species that were at risk from population effects due to CCAMLR fisheries mortalities, and the magnitude of the catch of seabirds, were both areas of high uncertainty at the onset of the fishery in the early 1990s. Research during this period showed that high bycatch of albatrosses and petrels was occurring in longline fisheries for Southern Bluefin Tuna Thunnus maccoyi in the Tasman Sea [19] and Patagonian Toothfish D. eleginoides around South Georgia [20]. These studies showed that these fisheries may have been killing tens of thousands of seabirds annually. Initial estimates of seabird captures in the CCAMLR longline fisheries during the 1995/1996 fishery indicated several thousand albatrosses were being caught from within the CCAMLR area. Higher numbers were possibly being within taken within the EEZs of CCAMLR parties which were within the CCAMLR area. At that time, only some areas had been assessed for bycatch rates, and anecdotal information suggested a widespread problem, although the magnitude of the bycatch was uncertain. The range of species caught included vulnerable and endangered species of albatross and petrel (Table 1).

It was recognised that adopting an approach of "sustainable catch" for management of the incidental deaths of seabirds in CCAMLR longline fisheries was neither appropriate nor possible. This approach would have required a thorough knowledge of the distribution, biology and ecology of all species at risk, together with an understanding of all sources of mortality including identification of which populations were being impacted by fishing mortality across a range of fisheries, spanning national and geographic boundaries. Calculating total seabird bycatch in a fishery can be challenging for many national fishery agencies, and to do this at the species-level for a wide geographical area was not considered feasible. Further, it was recognised that population responses due to 'unsustainable' fisheries take would have been impractical to measure in real time. This is because demographic responses could be delayed due to the life-history traits of albatross and petrel species, and vital parameters remain largely unknown for burrow-nesting petrel species. Therefore, colony-based monitoring to assess fisheries impacts was not pursued. In addition, many CCAMLR parties have domestic legislation that makes it an offence to take protected wildlife. As a result, a precautionary approach was adopted, with an objective to minimise seabird mortality in longline fisheries in the CCAMLR area to levels approaching zero. This objective has remained in place since the inception of the CCAMLR-
Table 1

Species for which information is considered as part of the CCAMLR-SRA and their IUCN status

\begin{tabular}{|c|c|c|}
\hline Species & Scientific name & IUCN status[21] \\
\hline \multicolumn{3}{|l|}{ Albatrosses } \\
\hline Tristan albatross & Diomedea dabbenema & Endangered \\
\hline Wandering albatross & Diomedea exulans & Vulnerable \\
\hline Royal albatross & Diomedea sanfordi & Endangered \\
\hline Southern royal albatross & Diomedea epomophora & Vulnerable \\
\hline Amsterdam albatross & $\begin{array}{l}\text { Diomedea } \\
\text { amsterdamensis }\end{array}$ & $\begin{array}{l}\text { Critically } \\
\text { endangered }\end{array}$ \\
\hline Antipodean albatross & Diomedea antipodensis & Vulnerable \\
\hline Black-browed albatross & $\begin{array}{l}\text { Thalassarche } \\
\text { melanophris }\end{array}$ & Endangered \\
\hline Buller's albatross & Thalassarche bulleri & Vulnerable \\
\hline Campbell albatross & Thalassarche impavida & Vulnerable \\
\hline Chatham albatross & Thalassarche eremita & $\begin{array}{l}\text { Critically } \\
\text { endangered }\end{array}$ \\
\hline Grey-headed albatross & $\begin{array}{l}\text { Thalassarche } \\
\text { chrysostoma }\end{array}$ & Vulnerable \\
\hline $\begin{array}{l}\text { Indian yellow-nosed } \\
\text { albatross }\end{array}$ & Thalassarche carteri & Endangered \\
\hline $\begin{array}{l}\text { Atlantic yellow-nosed } \\
\text { albatross }\end{array}$ & $\begin{array}{l}\text { Thalassarche } \\
\text { chlororhynchos }\end{array}$ & Endangered \\
\hline Light mantled albatross & Phoebetria palpebrata & Near threatened \\
\hline Salvin's albatross & Thalassarche salvini & Vulnerable \\
\hline Shy albatross & Thalassarche cauta & Near threatened \\
\hline Sooty albatross & Phoebetria fusca & Endangered \\
\hline \multicolumn{3}{|l|}{ Petrels } \\
\hline Southern giant petrel & Macronectes giganteus & Vulnerable \\
\hline Northern giant petrel & Macronectes halli & Near threatened \\
\hline White-chinned petrel & Procellaria aequinoctialis & Vulnerable \\
\hline Grey petrel & Procellaria cinerea & Near threatened \\
\hline
\end{tabular}

SRA methodology, despite greatly increased knowledge of the status and trends of albatross and petrel populations in recent years.

\subsection{Risk-assessment identification, analysis and evaluation of the risks}

The specialist ad hoc Working Group on Incidental Mortality Associated with Fishing, (IMAF) ${ }^{1}$ was established in 1994 to provide advice to the Scientific Committee of CCAMLR on seabird interactions. Updated advice from IMAF is taken to the CCAMLR Commission via the Scientific Committee on an annual basis. The information contributing to the CCAMLR-SRA is summarised below, drawing examples from the more recent annual analyses.

Risk of seabird mortality in fishing operations was initially identified for parts of the CCAMLR area wherein new and exploratory fisheries have been undertaken since the 1990s. The basic principle of the assessments has been

\footnotetext{
${ }^{1}$ The group was formerly called the Working Group on Incidental Mortality Associated with Longline Fishing (IMALF), but now covers trawl, pot and longline fishing methods. IMAF works in concert, but independently of the CCAMLR Working Group on Fish Stock Assessment, and these two groups prepare a joint report to the CCAMLR Scientific Committee.
} 
to identify the risk of capture of seabirds in fishing operations, rather than to examine the consequences of captures on populations of seabirds. Therefore, the risk rating applied describes the inherent risk to seabirds through using longline gear, and remains unchanged in response to changes in fishery practice (e.g. use of mitigation measures). Improvements in fishery performance are recognised by changes in the management responses, which are applied in an adaptive manner, as new information becomes available [4].

In 1997 the first risk assessment was carried out for the areas where proposals had been put forward for new and exploratory fisheries, as well as areas where existing fisheries operated. These assessments have been revised annually, and now include all parts of the CCAMLR area, regardless of whether a fishery is projected to operate in those areas for the next season. Seventeen areas of the CCAMLR area are used as units assessed in the CCAMLR-SRA, grouping Statistical subareas and smaller units (divisions) on ecological and geographical grounds (i.e. groups neighbouring areas on the basis of similarity) (Fig. 1). They range in area from 400,000 to $6,000,000 \mathrm{~km}^{2}$, and cover a range of marine habitats, with widely varying seabird communities and fishing opportunities (Table 2).

The assessment of the magnitude of general potential risk of bycatch of albatrosses and petrels [22] results in advice on:

(1) the timing of fishing seasons;

(2) the need to restrict fishing to night time;

(3) use of other methods at reducing (mitigating) bycatch;
(4) the level of observer coverage ( $\%$ hooks observed per vessel).

Ratings for each area are given on a subjective five-point scale:

(1) low;

(2) average-to-low;

(3) average;

(4) average-to-high;

(5) high.

The group of seabird species examined in the assessments includes albatross and petrel species known, or with potential to be caught in longline fisheries in the CCAMLR area (Table 1). This group does not include all seabird species that occur in the CCAMLR area (e.g. penguins and more coastal volant species that do not usually interact with longline gear are not included). Species are grouped in the assessment as follows [22]:

(1) 'breeding species in the area' means those seabird species considered to be at risk and which breed within the CCAMLR statistical area under consideration;

(2) 'breeding species known to visit the area' means seabird species which breed elsewhere within CCAMLR waters and are considered to be at risk, and which are known to visit the CCAMLR statistical area under consideration, as determined by satellite-tracking studies;

(3) 'breeding species inferred to visit this area' means seabird species which breed elsewhere within CCAMLR waters

Table 2

Risk Ratings applied to CCAMLR fishery areas in 2006 during the CCAMLR-SRA, and recommended fishing seasons

\begin{tabular}{|c|c|c|c|c|}
\hline $\begin{array}{l}\text { Sub area/ } \\
\text { division }\end{array}$ & $\begin{array}{l}\text { Sub area/division seabed } \\
\text { area }\left(1000 \mathrm{~km}^{2}\right)\end{array}$ & Area name & $\begin{array}{l}\text { Risk level in } \\
2006 \text { [22] }\end{array}$ & Recommended fishing season \\
\hline \multicolumn{5}{|c|}{ Atlantic Ocean Antarctic Area } \\
\hline 48.1 & 672 & Antarctic Peninsula Subarea & 3 & 1 May to 31 August \\
\hline 48.2 & 852 & South Orkney Subarea & 4 & 1 May to 31 August \\
\hline 48.3 & 1029 & South Georgia Subarea & 5 & 1 May to 31 August \\
\hline 48.4 & 940 & South Sandwich Subarea & 3 & 1 May to 30 September \\
\hline 48.5 & 2711 & Weddell Subarea & 1 & No recommendation \\
\hline 48.6 & 6426 & Bouvet Subarea & 2 & No recommendation \\
\hline \multicolumn{5}{|c|}{ Indian Ocean Antarctic Area } \\
\hline 58.4 .1 & 4526 & EWD i & 2 & No recommendation \\
\hline 58.4 .2 & 1566 & EWD ii & 2 & No recommendation \\
\hline $58.4 .3 \mathrm{a}$ and $\mathrm{b}$ & 1178 & EWD iiia and b (BANZARE Bank) & 3 & 1 May to 31 August \\
\hline $58.4 .4 \mathrm{a}$ and $\mathrm{b}$ & 2485 & EWD iv a and $\mathrm{b}(\mathrm{Ob}$ and Lena Banks) & 3 & 1 May to 31 August \\
\hline 58.5 .1 & 1091 & Kerguelen Division & 5 & 1 May to 31 August \\
\hline 58.5 .2 & 629 & Heard-McDonald Division & 4 & 1 May to 31 August \\
\hline 58.6 & 835 & Crozet Subarea & 5 & 1 May to 31 August \\
\hline 58.7 & 418 & Marion-Edward Subarea & 5 & 1 May to 31 August \\
\hline \multicolumn{5}{|c|}{ Pacific Antarctic Area } \\
\hline 88.1 & 3030 & Eastern Ross Sea Subarea & 3 & No recommendation \\
\hline 88.2 & 5033 & Western Ross Sea Subarea & 1 & No recommendation \\
\hline 88.3 & 2294 & Amundsen Sea Subarea & 2 & No recommendation \\
\hline
\end{tabular}

EWD $=$ Enderby-Wilkes Division. Risk levels are described as: 1 -low; 2 -average to low; 3 -average; 4 -average to high; 5 -high. See Fig. 1 for a map of these areas. 


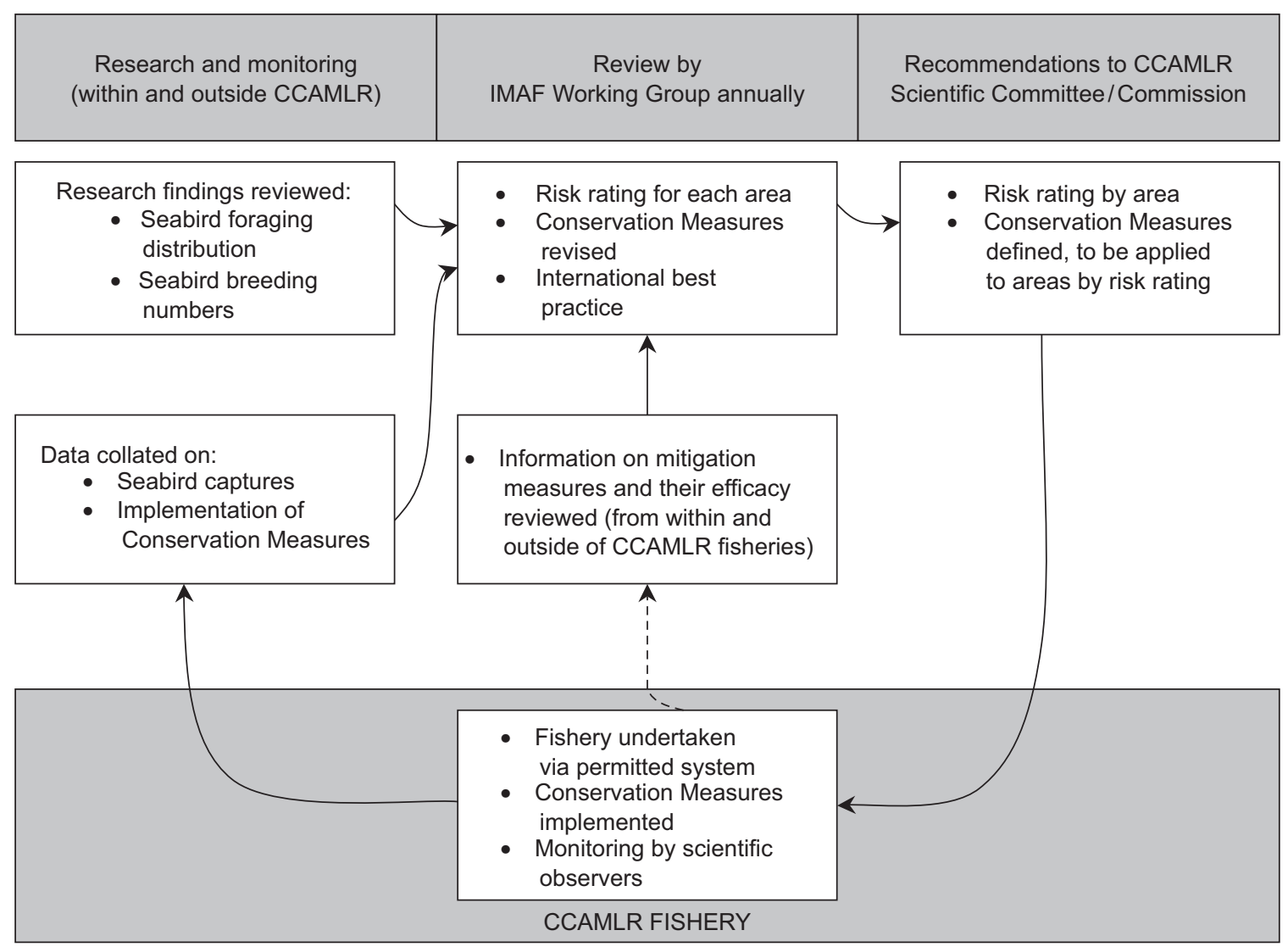

Fig. 3. Schematic representation of the method of applying the CCAMLR Seabird Risk Assessment, which occurs in an annual cycle of research, review, recommendations and operation of the fishery.

and are considered to be at risk, and which are thought to visit the CCAMLR statistical area under consideration, as determined by at-sea distributions derived from either at-sea sightings during the breeding season, or as published in the scientific literature;

(4) 'other species' means seabird species which breed outside CCAMLR waters and are considered to be at risk, and are known to occur in significant numbers in the CCAMLR statistical area under consideration.

The rating for each area is based on knowledge of the known-and inferred-potential for interaction of seabirds in these groups of seabirds with fisheries. The known potential interactions are based exclusively on the known ranges of breeding birds determined by recent satellitetracking studies (including species breeding outside the CCAMLR area, but visiting the area). These are considered to be minimum estimates of the home ranges of breeding populations, due to the small sample sizes of many of the studies. Recent collation of satellite-tracking studies in the Global Procellariiform Tracking Database has provided the basis for assessments since 2004 [5].

The inferred potential interactions are based on (a) ranges for breeding populations analogous to those determined by satellite-tracking at other breeding sites; and (b) at-sea distributions derived from band returns and seabird at-sea sightings during the breeding season as published in distribution atlases. To assess distributions for 'other species', information from the literature has been used, along with expert opinion from experienced fisheries observers with specialist seabird knowledge.

In the 2006 revision of the CCAMLR-SRA [22], riskassessment ratings for the seventeen areas varied between 1 and 5, with average (3) risk being the most common rating (5 areas) (Table 2).

These assessments, while based for a large part on published scientific information, also rely on the input of expert opinion from IMAF (Fig. 3).

\subsection{Management of risk}

The risk of seabird captures in CCAMLR longline fisheries has been managed by five primary measures: (1) restricting fishing seasons to avoid high-risk times of year for seabird mortalities (e.g. prohibit fishing in the summer months in high-risk areas); (2) line weighting regimes (varying depending on the type of fishing operation); (3) setting lines only at night; (4) setting a seabird bycatch limit of three seabirds per vessel per season; and (5) deployment of independent scientific observers to include $100 \%$ of vessels and observe the hauling of a high proportion $(25-80 \%)$ of hooks set per vessel. The measures for each area are tailored to the need to avoid interactions with seabirds of different species, and therefore vary 
Table 3

Conservation Measures of CCAMLR applied to areas of different risk rating under the CCAMLR-SRA for new and exploratory longline fisheries, to minimise the mortality of seabirds in longline fisheries in the CCAMLR area (after [23]: pp. 453)

\begin{tabular}{|c|c|c|}
\hline Risk rating & Mitigation requirements & $\begin{array}{l}\text { Observer coverage } \\
\text { recommended }\end{array}$ \\
\hline 1 -low & $\begin{array}{l}\text { - Strict compliance with standard seabird by-catch conservation measure }{ }^{\mathrm{a}} \text {. } \\
\text { - No need for restriction of longline fishing season. } \\
\text { - Daytime setting permitted subject to line sink rate requirement. } \\
\text { - No offal dumping. } \\
\text { - Vessels that catch a total of three birds shall revert to night setting. }\end{array}$ & $\begin{array}{l}20 \% \text { of hooks hauled } \\
50 \% \text { of hooks set }\end{array}$ \\
\hline 3 - average & $\begin{array}{l}\text { - Strict compliance with standard seabird by-catch conservation measure }{ }^{\mathrm{a}} \text {. } \\
\text { - Restrict longline fishing to period outside breeding season for at-risk species (May-August) }{ }^{\mathrm{b}} \text { unless line sink } \\
\text { rate requirement is met at all times. } \\
\text { - Daytime setting permitted subject to strict line sink rate requirements and seabird by-catch limits. } \\
\text { - No offal dumping. } \\
\text { - Vessels that catch a total of three birds shall revert to night setting. }\end{array}$ & $\begin{array}{l}40 \% \text { of hooks hauled } \\
95 \% \text { of hooks set }\end{array}$ \\
\hline $\begin{array}{l}4 \text {-average to } \\
\text { high }\end{array}$ & $\begin{array}{l}\text { - Strict compliance with standard seabird by-catch conservation measure. } \\
\text { - Restrict longline fishing to the period outside any at-risk species breeding season (May-August for all } \\
\text { species in areas with this risk rating) }{ }^{\text {b }} \text {. } \\
\text { - Strict line sink rate requirements at all times. } \\
\text { - No daytime setting permitted. } \\
\text { - No offal dumping. } \\
\text { - Vessels that catch a total of three birds shall revert to night setting. }\end{array}$ & $\begin{array}{l}45 \% \text { of hooks hauled } \\
95 \% \text { of hooks set }\end{array}$ \\
\hline 5-high & $\begin{array}{l}\text { - Strict compliance with standard seabird by-catch conservation measure }{ }^{\mathrm{b}} \text {. } \\
\text { - Restrict longline fishing to period outside at risk species breeding season (May-August for all species in } \\
\text { areas with this risk rating). } \\
\text { - Closed areas as identified by area. } \\
\text { - Strict line sink rate requirements at all times. } \\
\text { - No daytime setting permitted. } \\
\text { - Strict seabird by-catch limits of three birds per vessel in place. } \\
\text { - No offal dumping. }\end{array}$ & $\begin{array}{l}50 \% \text { of hooks hauled } \\
100 \% \text { of hooks set }\end{array}$ \\
\hline
\end{tabular}

\footnotetext{
${ }^{a}$ Conservation Measure 25-02 with the possibility of exemption to line weighting requirements, as provided by Conservation Measure 24-02.

${ }^{b}$ Note that species and months specified may vary between areas depending on the seabird assemblages breeding in a particular fishery area.

${ }^{\mathrm{c}}$ Likely to require two observers.
}

between areas. Table 3 sets out the conservation measures (CMs) required for the different fishing areas, based on their risk rating, as defined in 2006 [22].

$\mathrm{CMs}$ have been implemented that require vessels to follow strict procedures that are known to reduce or avoid the risk of seabird captures. The measures in place have evolved during the annual consideration by the mitigation and seabird experts within IMAF with increasing knowledge and technical developments [23]. The current CMs in the CCAMLR area particular to longline fisheries ${ }^{2}$ are:

- CM24-02 (2005) Line weighting for seabird conservation - sets a standard and a monitoring procedure for

\footnotetext{
${ }^{2}$ This list does not include measures that are common across all fishing methods, such as the need to carry observers, data reporting, dumping of rubbish or packaging.
}

line-sink rate for the two predominant demersal longline fishing methods (Autoline and Spanish longline).

- CM25-02 (2005) Minimisation of the incidental mortality of seabirds in the course of longline fishing or longline fishing research in the Convention Arearequires: that sink rates are maintained (either through line weighting or use of fishing gear with integrated weights); that lines are set during night-time; that offal dumping does not occur during setting; that streamer lines complying with a detailed performance-related specification are deployed; and that appropriate handling and release procedures are applied to captured seabirds to ensure survival of the birds where possible.

Two independent scientific observers are deployed on all longline vessels operating in the CCAMLR convention 
$\operatorname{area}^{3}$. Due to the need for rest breaks, fewer than $100 \%$ of fishing events are observed. Observers normally comprise one national and one international observer, the latter appointed by CCAMLR coordinators. This creates transparency in the monitoring of catch and implementaton of $\mathrm{CMs}$, both for target and non-target species.

\subsection{Monitoring and review}

IMAF reviews information annually, in the weeks before the CCAMLR Scientific Committee and Commission meetings. IMAF considers the rates of seabird bycatch reported by all vessels together with the levels of adherence with CMs and recommends any changes to risk ratings for fishery areas and to CMs. The group also provides recommendations on permitting of vessels seeking to fish in the CCAMLR area for the next year. This review is on the basis of the following:

(1) Conservation measures. New information about bycatch mitigation measures and their efficacy is reviewed. This information includes data about the operational aspects of mitigation measures currently in use in the CCAMLR area, as well as the results of experimental or observational trials of mitigation measures from CCAMLR fisheries and similar fisheries outside the CCAMLR area. Any substantive improvements in mitigation technology or performance are considered in the light of the need to revise the existing CMs. For example, research into the effectiveness of streamer lines in the Alaskan groundfish fishery [24] was considered by IMAF, and lead to revision of the specifications for CCAMLR streamer lines in CM25-02 (2005). Similarly, experimental work on line-sink rate carried out in New Zealand demersal longline fisheries for Ling Genypterus blacodes in 2004 [25] provided the basis for changes to the lineweighting provisions in CM24-02 (2005). These changes allowed vessels to use newly tested fishing line, with leadweight integrated into the core of the line, instead of external, clip-on weights. This led to safer working conditions for fishing crews, and improved sink-profiles and rates for fishing gear, as well as increased soak times for lines and improved fish catch rates.

(2) Seabird bycatch statistics. Capture rates of seabird species by area and by vessel are estimated, and causes of capture are examined at vessel or trip level. These are analysed to examine any trends in capture and to enable continual improvement in capture statistics and mitigation specifications. Observer coverage rates have been high, with $100 \%$ of vessels covered, and $25-80 \%$ of hooks observed per vessel. Therefore, estimates of total catch are produced by extrapolating the observed catch of seabird to the total effort, at vessel level (no error estimates are

\footnotetext{
${ }^{3}$ Observer coverage requirements may vary within member CCAMLR parties EEZs, but most follow the prescription for $100 \%$ observer coverage.
}

generated). This provides a robust and simple performance measure for monitoring seabird mortalities. Statistics are compiled by vessel and statistical subarea.

(3) Adherence to CMs. Very detailed observer protocols are in place to monitor whether the specifications for mitigation requirements are followed, and deviation from required performance is noted at a fishing-event level. Catches of high numbers of seabirds for a particular vessel are examined in light of implementation of the CMs. This review can affect the vessels likelihood of receiving a fishing permit in the following season, under some CCAMLR parties' area of jurisdiction.

(4) Seabird distribution and abundance. Information about seabird distribution and abundance is reviewed, where relevant to the CCAMLR-SRA rating. Continuing improvements in knowledge of seabird distribution, in particular through remote monitoring (such as satellitetracking, or geo-locator deployments) led to changes in risk ratings for CCAMLR fisheries areas. Changes in the risk ratings for CCAMLR fishery subareas occurred when the BirdLife International Global Tracking Database [5] became available, and extended the knowledge of the at-sea distribution of many species of seabird in the CCAMLR area. As a result, five changes in the risk rating were recommended in 2005. Three areas were upgraded, and two were down-graded as a result of this review.

(5) International instruments. CCAMLR Resolution 22/ XXV highlights the need for international actions to reduce the incidental mortality of seabirds arising from fishing. Despite the substantial reductions of seabird bycatch in the CCAMLR-regulated fisheries, some populations of albatrosses breeding in the CCAMLR area continue to decline significantly. Evidence suggests that incidental mortalities of breeding seabirds from the CCAMLR area occur in fisheries outside the CCAMLR area. Activities in EEZ fisheries, other RFMOs, intergovernmental agreements and other initiatives are thus reviewed, so that the IMAF Working Group remains abreast of information about improvements in fishery performance or governance. Particularly significant changes to the operation of the CCAMLR-SRA have occurred with the entry into force of the Agreement on the Conservation of Albatrosses and Petrels (ACAP), which now provides a central collation facility for relevant seabird demographic and distributional data ${ }^{4}$.

(6) Fishery practice. An informal review of changing practices within CCAMLR fisheries is undertaken, and requests for changes to $\mathrm{CMs}$ that result from evolving practice are considered by IMAF. For example, in 2004, the Commission accepted changes to CM24-02, allowing relaxation of night setting requirements, if specified line-weighting regimes were used, subject to a three-bird bycatch limit. These weighting regimes had been tested

\footnotetext{
${ }^{4}$ The collation and review of seabird abundance and distribution information has been undertaken by the Agreement on the Conservation of Albatrosses and Petrels (ACAP) since 2006. ACAP now provides annual summaries of relevant data to IMAF for review purposes.
} 
experimentally in New Zealand in fisheries of similar characteristic to the Dissostichus fishery and involved a number of vessels fishing in the CCAMLR area.

(7) Synthesis. Several factors are recognised as pivotal to the highly effective management of seabird bycatch in CCAMLR longline fisheries, excluding the areas managed under the EEZs of CCAMLR member countries [4].

Primary among these is the detailed annual review of information on fishery performance, the seabird species, and improvements in bycatch mitigation practice. This has resulted in revision to $\mathrm{CMs}$, ensuring that the measures are close to international best practice for the fishery at any time. This has meant that risk to seabird species has been minimised while fishing opportunities have been maximised. The time-tabling of CCAMLR technical and Commission meetings has meant that review and implementation of CMs has been particularly efficient. IMAF has operated for over 10 years and dedicates a significant amount of experts time in analysing the performance of the CCAMLR fisheries in seabird bycatch which is a unique and has been pivotal to its success.

Next, there are seasonal closures of fisheries in high-risk areas during the breeding period for seabirds when mortalities are most likely to occur, and are also most damaging to breeding populations. This measure created additional problems, while creating the potential for fishing effort to be displaced, and having a requirement for surveillance of fishing areas to ensure that closures were respected ${ }^{5}$, but has nevertheless proved extremely successful in reducing seabird bycatch rates.

Thirdly, the placement of independent scientific observers, who observe near to $100 \%$ of the hauls in the CCAMLR longline fishery, is identified as a key factor in achieving very low levels of seabird captures in CCAMLR longline fisheries in recent years. The scientific observers' roles in bycatch monitoring, and reporting on the implementation of CMs has provided high quality information, allowing an adaptive management approach to be undertaken rapidly and efficiently.

Finally, the continual improvement in the knowledge of population trends and distribution of seabirds has led to greater certainty in defining the risk of fisheries mortality across the CCAMLR area. This has occurred with advances in remote tracking technology, analytical techniques, and more comprehensive databases. This has been mirrored by continuing experimentation and innovation with mitigation measures, with measures proven to be effective rapidly adopted in CCAMLR longline fisheries.

In the next phase of development of CCAMLR fisheries, relaxation of seasonal fishery closures could occur ${ }^{6}$.

\footnotetext{
${ }^{5}$ CCAMLR continues to have a considerable problem with illegal, unreported and unregulated fishing [9], which is reviewed separately from the regulated fishery.

${ }^{6}$ For example, in 2006, Australia requested a relaxation of the seasonal closure for fisheries in CCAMLR Area 58.5.2 (Heard MacDonald
}

Increasing requests for fisheries to operate outside the current permitted season are being reviewed by IMAF. Recommendations to relax the closed seasons require an assessment by IMAF of the risk of seabird mortality, and means by which the fishery can avoid undue levels of capture of seabirds in high-risk areas.

In summary, an extensive system of ERA is in place in CCAMLR fisheries which allows a fully adaptive process for managing the risk of seabird mortalities. The performance of CCAMLR longline fisheries at reducing seabird captures has demonstrated the effectiveness of that approach. This therefore provides a useful model for other RFMOs seeking to manage seabird mortality.

\section{Comparison of RFMO provisions for reducing seabird mortality}

The RFMOs with specific tuna-fishing activities have recognised the need for review of their overall performance in their joint meeting in 2007 [26]. Small [27] extensively reviewed the performance of RFMOs in relation to environmental management and identified six RFMOs ${ }^{7}$, including CCAMLR, of particular relevance to the management of incidental mortality of seabirds in longline fisheries. Here we review the provisions in place in those RFMOs for managing incidental mortality of seabirds, in relation to the four key stages of ERA.

Using the CCAMLR process as a model for development of effective bycatch-reduction strategies, we identify four steps that RFMOs can follow, when dealing with seabird mortality problems in the fisheries they manage (Table 4). These steps mirror the classic ERA process discussed earlier in this paper. In the case of CCAMLR fisheries, steps 1-4 were undertaken within a period of 2 years, and the review and feedback in steps $2-4$ is ongoing. In some instances, revision of step 1 (setting objectives and problem formulation) may be required, but this has not yet occurred in the CCAMLR context.

The current frameworks in place for the six RFMOs show the progress in managing risk of seabird mortality. However, not all steps identified in this study have been undertaken in the treatment of seabird bycatch problems by each RFMO (Table 5).

(a) Establishing the context and problem formulation: All agreements recognise that a seabird bycatch problem exists, with resolutions recording the concern of

(footnote continued)

Division), and presented information to allow an assessment of the risk of captures of seabird, along with details of the catch-history and compliance with current conservation measures of the vessels proposing to fish in the area.

Convention for the Conservation of Southern Bluefin Tuna (CCSBT, CCAMLR, Inter-American Tropical Tuna Commission (IATTC), International Convention for the Conservation of Atlantic Tunas (ICCAT), Indian Ocean Tuna Commission (IOTC), and Western and Central Pacific Fisheries Commission (WCPFC). 
Table 4

Stages in the development of bycatch management for RFMOs. These have occurred incompletely for all RFMOs reviewed except in CCAMLR longline fisheries where the full suite of steps has been undertaken

Stage of development of bycatch management process

\section{Recognition of a bycatch} problem and establishment of objectives for addressing bycatch

\section{Assessment of risk- identification, analysis and assessment}

3. Measures put in place to reduce bycatch
Management response-examples of key components

(a) Establish a seabird bycatch resolution

(b) Establish a technical bycatch working group

(c) Develop bycatch management objectives.

(d) Gather information specific to the fishery to characterise the problem

(a) Conduct risk assessment(s) to ensure that measures are applied in areas of highest relative risk of bycatch occurring.

(b) Identify highest priority areas for management (e.g. on the basis of catch rates, total estimates, and vulnerability of the seabird species caught)

(a) Implement mandatory measures (e.g. regulations) known to be effective at reducing bycatch —usually technical solutions such as mitigation devices

(b) Reduce fishing opportunities to avoid high risk areas/seasons

(c) Impose bycatch limits that reduce risk to seabird populations and create incentives for fishers to develop effective mitigation strategies that suit their operations.

(a) Monitor catches via independent observer coverage and fisher log-books

(b) Monitor implementation of mitigation requirements

(c) Identify new mitigation measures or strategies

(d) Impose penalties on vessels or groups not complying with mandatory measures or exceeding bycatch limits

(e) Revise risk ratings on the basis of new information

(f) Relax measures where possible in light of improved performance or evolution in practice members about the issue. CCAMLR and IOTC are the only two agreements to explicitly identify the aim of reducing seabird bycatch in the seabird resolutions they have adopted.

(b) Undertaking formal risk assessment: Although the process of ERA has been established for several decades in the wider field of environmental management, its uptake in the area of management of fisheries bycatch has been slow. Formal risk assessment for seabird bycatch currently occurs only in CCAMLR fisheries, although risk-assessment processes are now being established in WCPFC and ICCAT. Intuitively, it would appear that such assessments would reduce wastage of resource, or inappropriate imposition of costly measures, either in terms of lost fishing opportunities or implementation of mitigation requirements, or inadequate environmental protection for species populations that may be damaged by fishing activities.

(c) Identification of risk and implementation of management measures to address risks: Four agreements have implemented measures intended to reduce bycatch (WCPFC, CCSBT, IOTC and CCAMLR), by way of mitigation devices deployed on vessels. A significant exception exists for the Swordfish fishery for IOTC $^{8}$,

\footnotetext{
${ }^{8}$ The Scientific Committee of IOTC recommended removing this exemption in June 2007, although this has not yet been considered by the Commission of IOTC.
}

which is not required to use mitigation measures specified for the remaining fisheries. Only CCAMLR has implemented a reduced fishing season in response to seabird bycatch concerns. CCAMLR is the sole RMFO that prohibits offal discharge during line setting, as a mitigation measure.

Data recording via observer coverage is most comprehensive for CCAMLR with collection and exchange of data a mandatory requirement, at vesselor event-level. Requirements under WCPFC have been defined, but are yet to enter into force. For all other RFMOs, data collection and exchange is currently either voluntary (IOTC, ICCAT, IATTC), or are not covered by the agreement (CCSBT). CCAMLR, in contrast to the other agreements, has fishery access penalties associated with the review of performance of fisheries against mitigation requirements either through area-leaving rules for catching over the three-bird bycatch limit, or where CMs have not been implemented. These penalties may be pursued differently by flagstates permitting vessels to fish in the CCAMLR areas of their jurisdictions.

(d) Monitoring and review: Annual assessment and scrutiny of the implementation of CMs occurs only in CCAMLR fisheries, although it could be argued that IATTC has no mandatory seabird mitigation measures, so compliance monitoring is not relevant in this case. Further, assessments of seabird bycatch for the sum of fisheries at the level of the whole agreement does not 
Table 5

Regional fishery management organisations using longlining methods and identifying seabird mortality as a key risk

\begin{tabular}{|c|c|c|c|c|}
\hline $\begin{array}{l}\text { Agreement } \\
\text { acronym, year } \\
\text { entered into force, } \\
\text { and name of the } \\
\text { agreement }\end{array}$ & $\begin{array}{l}\text { 1. Establishing the context and } \\
\text { objectives for dealing with } \\
\text { bycatch } \\
\text { (a) Resolution on bycatch } \\
\text { (b) Bycatch Working Group }\end{array}$ & $\begin{array}{l}\text { 2. Risk assessment } \\
\text { through identification, } \\
\text { analysis and evaluation of } \\
\text { the risks }\end{array}$ & $\begin{array}{l}\text { 3. Management of the risk via establishment } \\
\text { measures known to reduce bycatch }\end{array}$ & $\begin{array}{l}\text { 4. Monitoring and review } \\
\text { (a) observer programme; } \\
\text { (b) monitoring and reporting of bycatch; and } \\
\text { (c) monitoring of compliance with bycatch reduction } \\
\text { measures }\end{array}$ \\
\hline
\end{tabular}

CCAMLR-1982

(a) Resolution R5/VII (1989) Minimisation of the incidental mortality of seabirds in the course of longlining.

Resolution 22/XXV (2006) International actions to reduce the incidental mortality of

Convention for the Conservation of Antarctic Marine Living

Resources

ICCAT-1969

International

Convention for

the Conservation

of Atlantic Tunas

CCSBT-1994

Convention for

the Conservation

of Southern

Bluefin Tuna

IOTC-1996

Indian Ocean

Tuna Commission seabirds arising from fishing.

(b) Ad hoc IMAF Working Group established with the objective to reduce seabird bycatch to near zero levels.

(a) Resolution 02-14 Resolution by ICCAT on incidental mortality of seabirds

(b) Subcommittee on Bycatch formed, and in 2005 made a suite of recommendations to document and research bycatch issues in the fishery.

(a) Recommendations Relating to Ecologically Related Species, Especially the Incidental Mortality of Seabirds by Longline Fishing (1997) Attachment E Report to the Meeting of CCSBT3.

Attachment U Report to the Meeting of CCSBT4.

(b) Ecologically-Related Specie Working Group established

(a) Resolution 06/04 On Incidental Mortality of Seabirds recognises the need to strengthen mechanisms to
Risk assessment reviewed

annually, process

described in this paper. protect seabirds in the Indian

Resolution $02-14$

Resolution by ICCAT on incidental mortality of seabirds that a risk assessment should be developed when feasible and appropriate.

\section{None in place}

None in place
CM 25-02 (2005) Minimisation of the incidental mortality of seabirds in the course of longlining requires restricted fishing seasons, night setting, bait thawing, use of streamer lines, minimsation of discharge of fisheries waste and intent for sinking baits as quickly as possible.

CM25-01 (1996) regulates use and disposal of plastic packaging bands

CM24-02 (2005) specifies line weighting for longline vessels

Report of the 4th CCSBT MeetingAttachment $\mathrm{U}$ requires mandatory use of streamer lines vessels of all CCSBT parties fishing below of $30^{\circ} \mathrm{S}$ and provides guidelines for the design and deployment of streamer lines. Educational pamphlets have been developed and distributed to fishers

OTC have requested that a risk assessment be developed for consideration in 2007. IOTC have Resolution 06/04 in place (agreed 2006) requiring streamer lines to be used south of 30 degrees $\mathrm{S}$. There is an exemption a) $100 \%$ of vessels observed in longline fisheries, by independent, international observers.

(b) CM23-04 (2000) requires mandatory reporting of seabird interactions, via observer reports at shot-byshot level.

(c) Annual review of implementation of Conservation Measures at fishing event- and vessel-level by IMAF.

(a) Observer coverage encouraged, but not mandatory.

(b) Resolution 02-14 encourages collection and voluntary reporting of information on seabirds including incidental captures.

(c) No compliance monitoring at Commission level for seabird provisions is documented

(a) Around $10 \%$ of catch is observed by country observers for catch monitoring of target species on a voluntary basis.

(b) Voluntary reporting of incidental catch of seabirds (Report of CCSBT3)

(c) No compliance monitoring at Commission level fo seabird provisions is documented

(a) Observer coverage not mandatory

(b) Resolution 06/04 On Incidental Mortality of Seabirds requires IOTC to develop means of recording and exchanging data on seabird interactions within one year, and to collect and provide all available data to 


\begin{tabular}{|c|c|c|c|c|}
\hline $\begin{array}{l}\text { Agreement } \\
\text { acronym, year } \\
\text { entered into force, } \\
\text { and name of the } \\
\text { agreement }\end{array}$ & $\begin{array}{l}\text { 1. Establishing the context and } \\
\text { objectives for dealing with } \\
\text { bycatch } \\
\text { (a) Resolution on bycatch } \\
\text { (b) Bycatch Working Group }\end{array}$ & $\begin{array}{l}\text { 2. Risk assessment } \\
\text { through identification, } \\
\text { analysis and evaluation of } \\
\text { the risks }\end{array}$ & $\begin{array}{l}\text { 3. Management of the risk via establishment } \\
\text { measures known to reduce bycatch }\end{array}$ & $\begin{array}{l}\text { 4. Monitoring and review } \\
\text { (a) observer programme; } \\
\text { (b) monitoring and reporting of bycatch; and } \\
\text { (c) monitoring of compliance with bycatch reduction } \\
\text { measures }\end{array}$ \\
\hline
\end{tabular}

Ocean and with the aim of reducing seabird bycatch to zero levels.

(b) Working Party on

Ecosystems and Bycatch (first met 2005)

\section{WCPFC-2004}

Western and Central Pacific Fisheries

Commission

\section{IATTC-1950} Inter-American Tropical Tuna Commission (a) WCPFC Convention Article 5 sets out the need for target species, Article 6 states that data collection programmes will be established.

(b) Working Group is being developed under

Conservation and Management Measure 2006-07.

(a) Resolution C-05-01 in relation to seabird bycatch on seabird interactions and provision of an assessment of the impact of incidental catch of seabirds.

(b) Working Group on Stock Assessment considers

bycatch. No specific bycatch working group. reducing impacts on nonencourages collection of data for swordfish vessels using the American

Under development in Conservation and Management Measure 2007 2006-02 to mitigate the impact of fishing for highly migratory fish stocks on seabirds (mandatory) requires that two mitigation measures be used in areas south of $30^{\circ} \mathrm{S}$ and north of $23^{\circ} \mathrm{N}^{\mathrm{a}}$.

Measures identified include side setting with bird curtain and weighted branch lines; night setting; tori line; weighted branch lines; deep setting line shooter; blue-dyed bait;

underwater setting chute; and management of offal discharge

Resolution C-05-01 Resolution on incidental mortality of seabirds recommends that an assessment is provided to identify geographic areas where there could be interactions between longline fisheries and seabirds. This is under development in 2007.
None currently established, but Resolution C-05-01 requires that this be developed in 2007. IATTC has commissioned research on albatross population response to fisheries which addresses these issues. System, under review in 2007.

the Commission on interactions with seabirds. Recommendation 05/09 On Incidental Mortality of Seabirds encourages voluntary collection and provision of all available information on interactions with seabirds and the development of an assessment of impact of incidental catch on seabirds in the IOTC area.

(c) No compliance monitoring at Commission level for seabird provisions is documented

(a) Regional Observer Programme established in 2007, but observer coverage currently not mandatory.

(b) Conservation and Management Measure 2006-02 to mitigate the impact of fishing for highly migratory fish stocks on seabirds (mandatory) requires the Scientific Committee to review any information about mitigation measures and their improvements and data on seabird interactions.

(c) No compliance monitoring at Commission level for seabird provisions is documented

(a) Observer programme is not mandatory on longline vessels.

(b) Resolution C-05-01 Resolution on incidental mortality of seabirds (voluntary) encourages collection and provision of all available information on interactions with seabirds, including incidental catches.

(c) Not applicable as there are no mandatory measures for seabirds, although a Compliance Working Group monitors vessel requirements for other measures.

${ }^{\text {a }}$ Due to be implemented on 1 January 2008 for vessels larger than $24 \mathrm{~m}$ length and 31 January 2009 for vessels of less than $24 \mathrm{~m}$ length. 
occur under in the agreements other than in CCAMLR. Examination of bycatch levels and trends across fisheries under each agreement is therefore not possible. As a result, there appears to be little opportunity to assess the efficacy of mitigation measures used by most RFMOs, and to understand if reduction of seabird bycatch has occurred.

\section{Summary}

This review suggests that there is scope for improvement in the process of managing risk to seabirds from fishing across the RFMOs that overlap most with albatrosses and petrel distributions. The four fundamental steps of ERA: (a) establishing the context and problem formulation; (b) undertaking formal risk assessment; (c) identification of risk and implementation of management measures to address risks; and (d) monitoring and review; have been instrumental in providing effective management and reduction of seabird bycatch in CCAMLR fisheries. Adoption of this or a similar process may assist other RFMOs in building robust mechanisms to deal with seabird or other bycatch problems. Most agreements have not undertaken (or are only now undertaking) risk assessments for seabird mortality, which appears to be a vital step in targeting resources to reduce this environmental risk. Given that incidental bycatch of seabirds also occurs within EEZs, adoption of this framework within EEZs would be a significant advance.

\section{Acknowledgements}

We are grateful to the members of IMAF who have provided stimulating discussion and encouragement in the production of this paper, in particular, Kim Rivera, Ben Sullivan, Graham Robertson, Ed Melvin, Johanna Pierre, Malcolm McNeill, Carlos Moreno, Tatiana Neves and Neville Smith, along with Eric Appleyard of the CCMALR secretariat for assistance with some figures and tables.

\section{References}

[1] Tuck GN, Polacheck T, Croxall JP, Weimerskirch H. Modelling the impact of fishery by-catches on albatross populations. Journal of Applied Ecology 2001;38:1182-96.

[2] Baker GB, Gales R, Hamilton S, Wilkinson V. Albatrosses and petrels in Australia: a review of their conservation and management. Emu 2002;102:71-97.

[3] Indian Ocean Tuna Commission. Resolution 06/04. On Reducing incidental bycatch of seabirds in longline fisheries 〈www.iotc.org >, 2006. Accessed 04/07/2007.

[4] Croxall JP, Rivera K, Moreno CA. Seabird by-catch mitigation: The Southern Ocean (CCAMLR) experience. Chapter 8, Working with fisheries to reduce by-catches, Case study 7. In: Kennelly SJ, editor. By-catch reduction in the world's fisheries. Reviews: Methods and Technologies in Fish Biology and Fisheries, vol. 7. Berlin: Springer; 2007. p. 235-88.
[5] BirdLife International. Tracking ocean wanderers: the global distribution of albatrosses and petrels. Results from the global procellariiform tracking workshop, 1-5 September 2003, Gordon's Bay, South Africa. Cambridge, UK: BirdLife International; 2004.

[6] Food and Agriculture Organisation of the United Nations. International plan of action for reducing incidental catch of seabirds in longline fisheries. Rome: FAO; 1999.

[7] Lokkeborg S, Thiele W, editors. Report of the FAO/BirdLife South American workshop on implementation of NPOA - seabirds and conservation of albatrosses and petrels, Valdivia, Chile, 2-6 December 2003. Rome: Food and Agriculture Organisation of the United Nations; 2004.

[8] Hunt C. Concern for Southern Ocean fish stocks and bird populations. Marine Policy 2006;20:357-9.

[9] Scientific Committee for the Conservation of Antarctic Marine Living Resources. Report of the 25th meeting of the scientific committee, Hobart, Australia, 23-27 October 2006. Hobart: CCAMLR; 2006.

[10] Commission for the Conservation of Antarctic Marine Living Resources. Report of the 16th meeting of the commission, Hobart, Australia, 27 October-7 November 1997. Hobart: CCAMLR; 1997. p. 18 , paragraph 6.46 .

[11] Link JS, Broadziak JKT, Edwards SF, Overholtz WJ, Mountain D, Jossi JW, et al. Marine ecosystem assessment in a fisheries management context. Canadian Journal of Aquatic Sciences 2002;59: 1429-40.

[12] Crawford C. Qualitative risk assessment of the effects of shellfish farming on the environment in Tasmania, Australia. Ocean and Coastal Management 2003;46:47-58.

[13] Hayes EH, Landis WG. Regional ecological risk assessment of a near shore marine environment: Cherry Point, WA. Human and Ecological Risk Assessment 2004;10:299-325.

[14] Hobday AJ, Smith A, Webb H, Daley R, Wayte S, Bulman C, et al. Ecological risk assessment for the effects of fishing: methodology. R04/1072. Canberra: Australian Fisheries Management Authority; 2006.

[15] United States Environmental Protection Agency. Framework for ecological risk assessment. EPA/630/R-92/001, United States Environmental Protection Agency, 1992.

[16] Standards New Zealand and Standards Australia. Environmental risk management-Principles and process. Standards Australia/Standards New Zealand. Wellington: Standards New Zealand; 2006.

[17] Onley D, Scofield P. Albatrosses, petrels and shearwaters of the world. Princeton, NJ: Princeton University Press; 2007.

[18] Text of the Convention on the Conservation of Antarctic Marine Living Resources. Statement by the Chairman of the conference on the Conservation of Antarctic Marine Living Resources <http:// www.ccamlr.org/pu/e/e_pubs/bd/toc.htm $\rangle$. Accessed 5/7/07.

[19] Brothers N. Albatross mortality and associated bait loss in the Japanese longline fishery in the Southern Ocean. Biological Conservation 1991;55:255-68.

[20] Dalziell J, De Poorter M. Seabird mortality in longline fisheries around South Georgia. Polar Record 1993;29:143-5.

[21] International Union for the Conservation of Nature 2006 〈www.redlist.org 〉. Accessed 15 February 2007.

[22] SC-CAMLR XXIV/BG/26. IMAF risk assessment of fisheries by statistical area. Ad hoc Working Group on Incidental Mortality Associated with Fishing. Hobart: CCAMLR; 2006.

[23] Conservation Measures in force in CCAMLR fisheries. 〈http:// www.ccamlr.org/pu/e/e_pubs/cm/drt.htm $\rangle$. Accessed 20/07/07.

[24] Melvin EF, Parrish JK, Dietrich KS, Hamel OS. Solutions to seabird bycatch in Alaska's demersal longline fisheries. Project A/FP-7, WSG-AS 01-01. Seattle: Washington Sea Grant; 2001.

[25] Robertson G, McNeill M, Smith N, Wienecke B, Candy S, Olivier F. Fast sinking (integrated weight) longlines reduce mortality of whitechinned petrels (Procellaria aequinoctialis) and sooty shearwaters 
(Puffinus griseus) in demersal longline fisheries. Biological Conservation 2006;132:458-71.

[26] Network of Tuna Agencies and Programs. Report of the joint meeting of tuna RFMOs 22-26 January 2007, Kobe, Japan. Network of Tuna Agencies and Programs; 2007 〈http://www.tuna-org.org/
Documents/other/Kobe\%20Report\%20English-Appendices.pdf $>$. Accessed 20/7/07.

[27] Small C. Regional Fisheries Management Organisations. Their duties and performance in reducing bycatch of albatrosses and other species. Cambridge, UK: BirdLife International; 2005. 